$$
\begin{aligned}
& \text { اثرات انسداد مجراى صفراوى بر مورفولوزى ناحيه حركتى قشر مغز و ميزان بروتئين } \\
& \text { كانالهاى آب نوع جهار در موشهاى هواى صحرايى نر بالغ } \\
& \text { دلارام اسليمى اصفهانى'، شهربانو عريان'، محمد نبيونى 'ّ و طليعه السادات حسينى نيا' }
\end{aligned}
$$

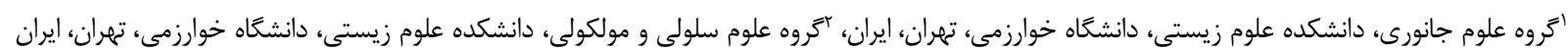

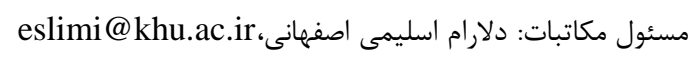

جكيده. عمل كردهاى معيوب حركتى در حيوانات كلستاتيك گزارش شده است. اين اختلال در عمل كرد و مركَ نورونهاى حركتى بسيار به تغييرات در محيط

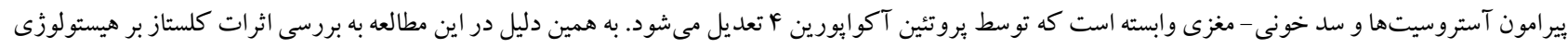

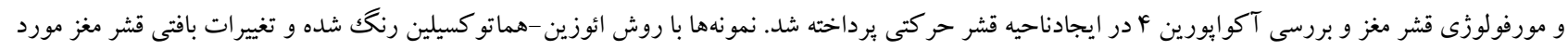

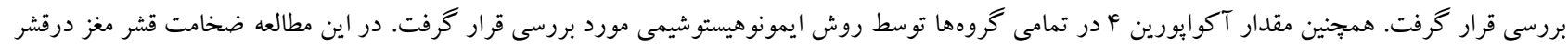

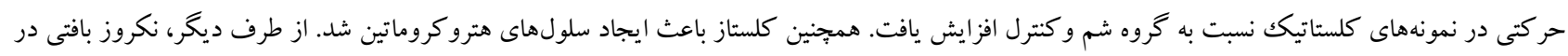

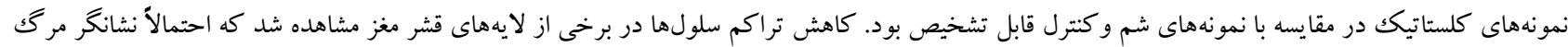

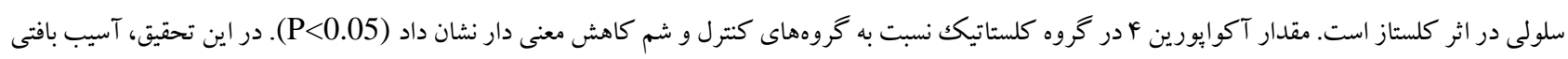

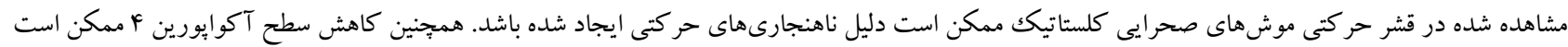
باعث آسيب نورونهاى حر كتى گردد.

وازههاى كليدى. ايمونوهيستوشيمى، فعاليت حركتى، كلستاز، نكروز، هتروكروماتين

\title{
The effects of bile duct ligation on motor cortex region morphology and aquaporin 4 protein concentration in male Wistar rats
}

\author{
Delaram Eslimi Esfahani ${ }^{1}$, Shahrbanoo Oryan ${ }^{1}$, Mohammad Nabiuni ${ }^{2}$ \& Talieh Sadat Hosseinynia $^{1}$ \\ ${ }^{1}$ Department of Animal Biology, Faculty of Biological Sciences, Kharazmi University, Tehran, Iran; ${ }^{2}$ Department of \\ Cell and Molecular Sciences, Faculty of Biological Sciences, Kharazmi University, Tehran, Iran \\ Correspondent author: Delaram Eslimi Esfahani, eslimi@khu.ac.ir
}

\begin{abstract}
Impaired motor functions were reported in cholestatic animals. This disorder in the function and death of motor neurons is highly dependent on changes in the environment around astrocytes and the blood-brain barrier, which is moderated by the aquaporin 4 protein. For this reason, the effects of cholestasis on motor cortex histology and morphology and aquaporin 4 protein levels were investigated in this study. Samples were stained by hematoxylin-eosin method . Histological changes in cortical brain were investigated. The amount of AQP4 protein in control, sham, and experimental groups were tested by immunohistochemistry. The thickness of motor cortex in cholestatic samples increased in comparison with the control and sham groups. Also, cholestasis caused wrinkle chromatic nuclei. On the other hand, tissue necrosis was detected in cholestatic group compared with sham and control groups. Reduction of cells densities in some cortical layers has been observed, which is probably indicative of cholestasis-induced cell death. AQP4 expression significantly decreased in BDL $(\mathrm{p}<0.05)$, but not in other groups $(\mathrm{P}<0.05)$.In this study, the pathology of motor cortex, which has also been associated with the decrease of neurons, could be considered the cause of motion abnormalities and AQP4 level reduction in cholestatic rats.
\end{abstract}

Keywords. cholestasis, immunohistochemistry, motor function, necrosis, wrinkle chromatic nuclei 
نشانهاى اختلالات حر كتى در تشخيص بيمارىهاى كبدى داراى

اهميت است (Mechtcheriakov et al., 2005). كنترل حر كات توسط كورتكس حركتى، شامل مناطقى از جمله

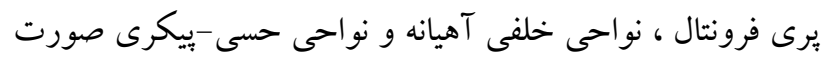

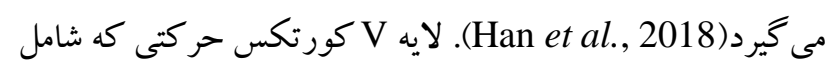

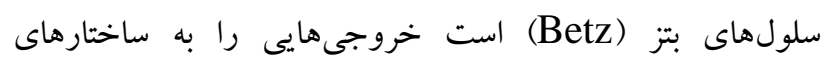

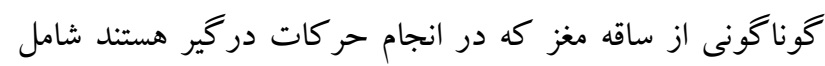

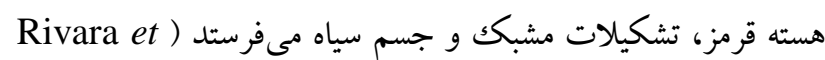
ز از رفتارهاى حركتى ساده مثل حركات تكرارى يكى انگشت تا

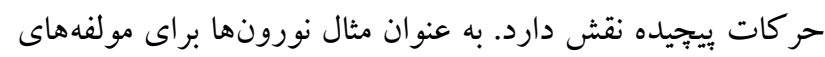

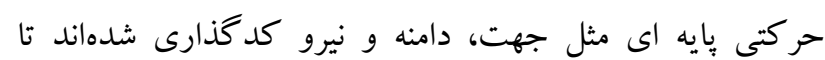
حر كات با سهولت انجام شوند ) Hatsopoulos et al., 2001;

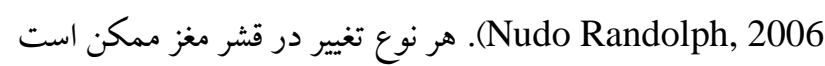

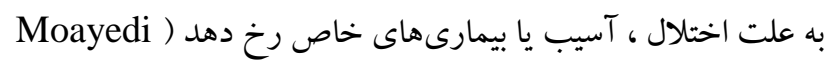
(et al., 2012; Nakamura et al., 2001 اختلالات كبدى عمل كردهاى معيوب حر كتى مشاهده مىشود، در

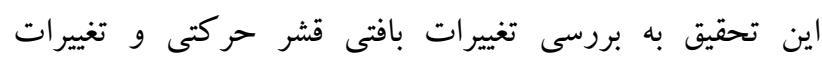

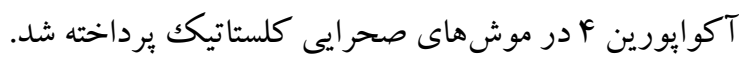

\section{مواد و روشها} حيوانات و شرايط آزمايش

در اين مطالعه بنيادى از إب سر موش صحرايى نر نزاد ويستار

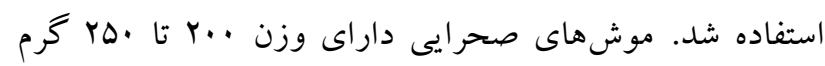

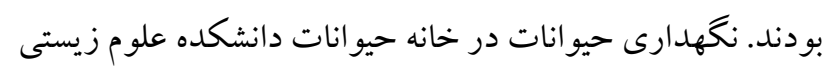

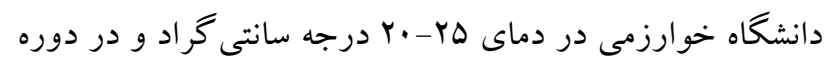

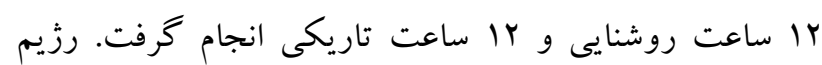
غذايى هماند ساير موشهاى صحرايى بوده و محدوديتى وجود

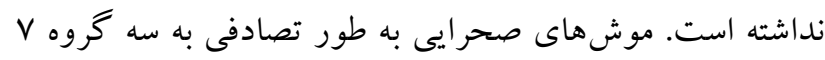

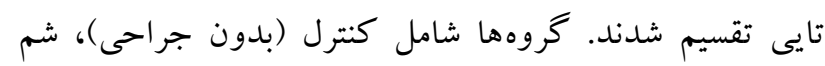

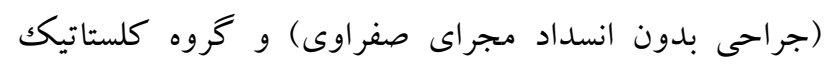

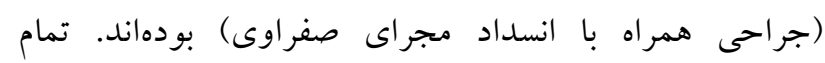

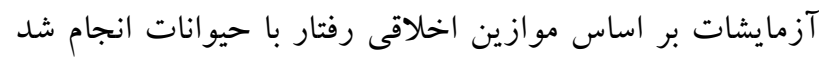

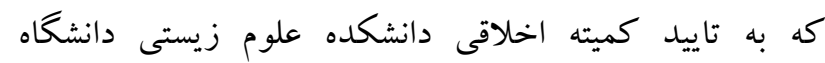
خو ارزمى رسيده است. جراحى كلستاز
مقل

كلستاز به اختلال در جريان صفرا در هرنقطه اى از غشاء قاعده -

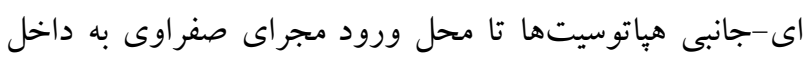
دئودنوم اطلاق مىشود (Tripodi et al., 2012). اين بيمارى ممكن است به صورت خارج كبدى در اثر انسداد مجر ایى صفراوى،

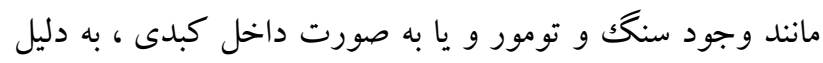
اختلال در تشكيل صفرا توسط هياتوسيتها و سلولهاى مجارى صفراوى مانند نقص زنتيكى يا اثر زيان آور برخى دارئ داروها ايجاد كردد ) Thomson \& Shaffer, 2008; Rodríguez-Garay, 2003). محل شروع اين نوع كلستاز مى تواند در قسمتهاى مختلف كانف

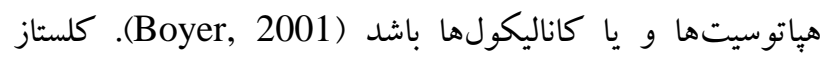

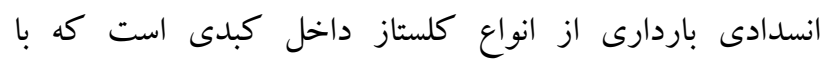
فاكتورهاى هورمونى، عفونى و محيطى آغاز شده و در سه ماهه سوم

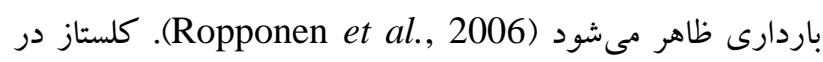

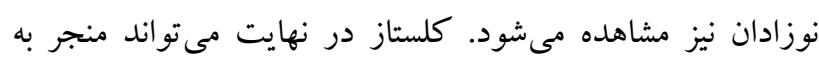
فيبروز و سيروز كبدى گردد.

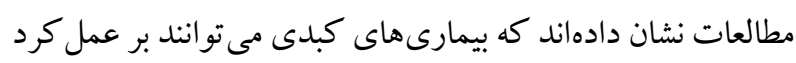
مغز تاثير كذارند. هياتيكك انسفالوياتى يكك سندروم عصبى -رواني

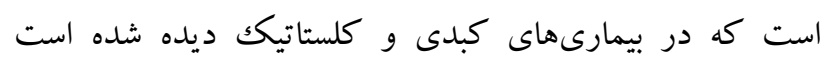

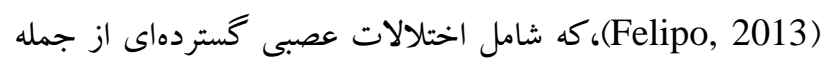
تغييرات سيكل خواب و بيدارى، اختلال عمل كردهاى شناختى و و حركتى و هماهنكى بين آنها است (Sheen et al., 2010).

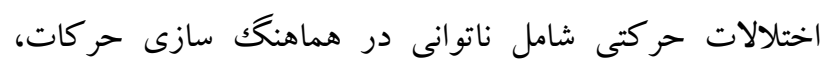
لرزش، كندى حركات انخشتان و تغيير دست خط، كشيدن اشكال و غيره هستند ) Butz et al., 2010; Bataveljić et al., 2012 (Guillermo et al., 2008; Mechtcheriakov et al., 2005 اختلال در هماهنكى ماهيجه اى و نيز اختلال در اعمال حر كتى در موش ها با مجر اى صفر اوى بسته نيز مشاهده شده است ( al., 2009; Butterworth et al., 2009; Dhanda et al.,

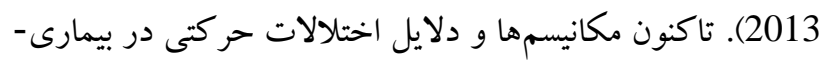
هاى كبدى مشخص نشده است (2013)

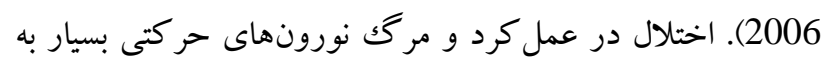
تغييرات در محيط بيرامون آستروسيتها و سد خونى -مغزى وابسته است كه توسط بروتئين آكوايورين ع تعديل مىشود ( Bataveljić

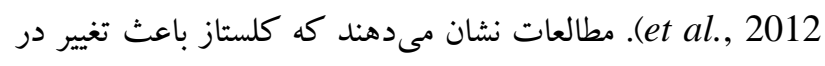

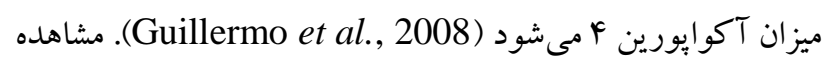


جهار درجه سانتيخر اد دراتاق مرطوب ودر كنترل منفى، برشها فقط

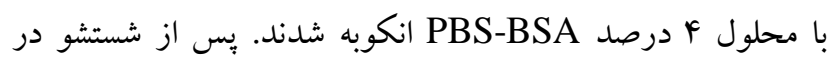

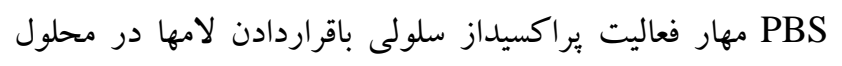

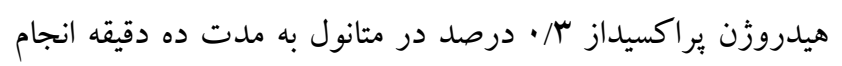

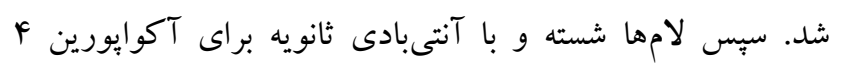

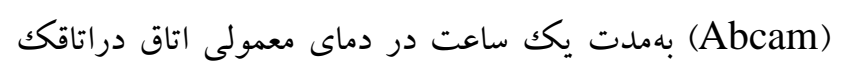

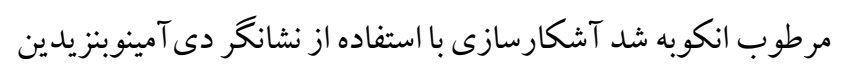
(DAB) (Laboratories, Inc., Montgomery, Tx) قهوه اى انجام گرفت. سبس آناليز برشها با ميكروسكوب نورى (Ziess)

\section{روش تجزيه و تحليل اطلاعات}

تجزيه وتحليل اطلاعات بوسيله شاخصهايل وان آمار توصيفى نظير ميانكين

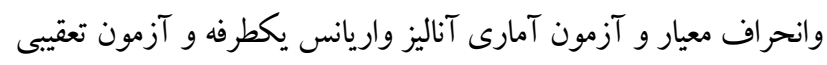
توكى انجام شد. سطح معنى دارى نيز هـ/ • در نظر كرفته شد.

\section{نتايج}

دو هفته يس از جراحى انسداد مجراى صفراوى، موشهاى

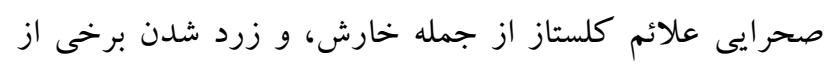

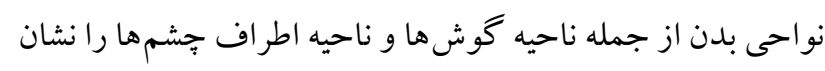

دادند.

نتايج حاصل از بررسىهاى هيستولوزيك،، نشان دهنده تغييرات

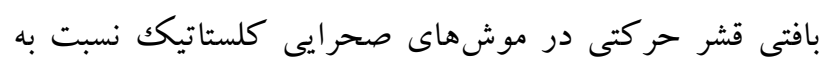

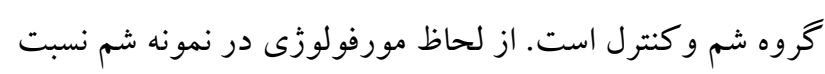

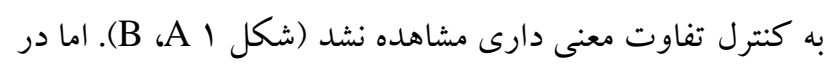

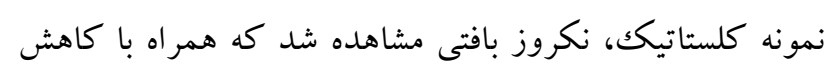

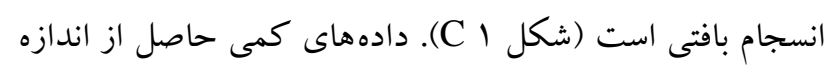

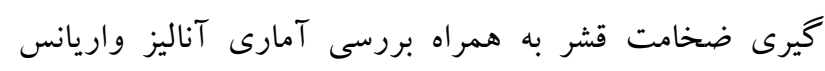
يكطرفه و آزمون تعقيبى تو كى كه در جدول إن آورده شده است، افزايش ضخامت در نمونههاى كلستاتيكك را در مقايسه با نمونه -

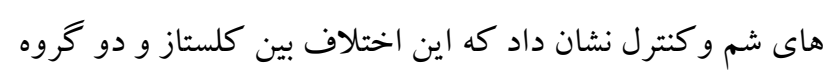

ديغر معنى دار (p-value>0.05) است (جدول (1) ).

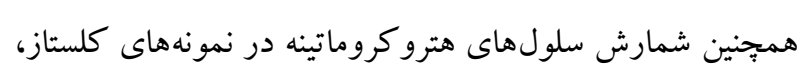
شم وكنترل در جدول ا آورده شده است. بررسى آمارى آناليز واريانس يكك طرفه و آزمون تعقيبى توكى دادههاى حاصل اصل از اين
بستن مجراى صفراوى مدل معروفى از بيمارى كبدى است

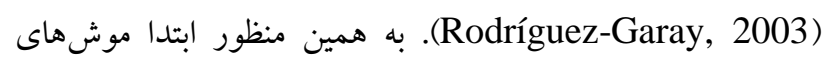

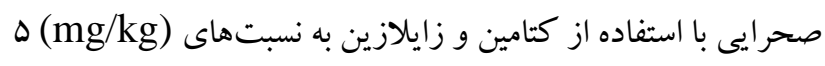

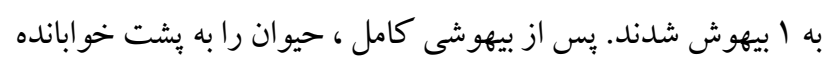

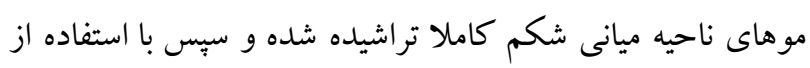

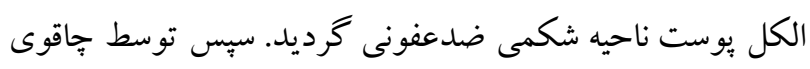

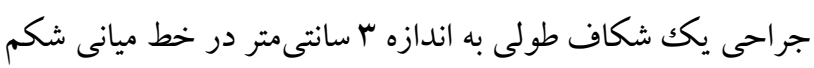
ايجادكرده و در دو مرحله يوست و عضلات جدار شكم باز شدند.

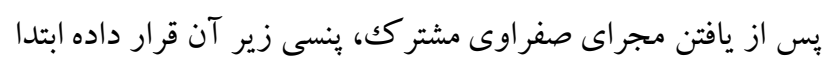

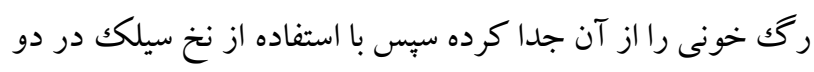

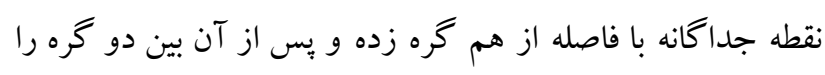

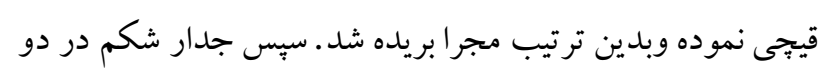

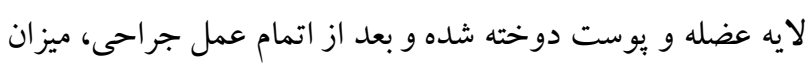

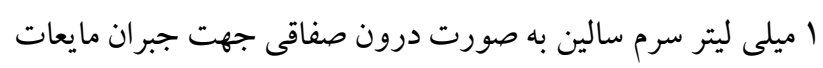

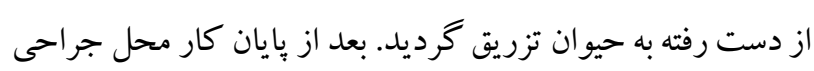
با بتادين كاملاً ضدعفونى شد.

\section{روش بررسى بافتى و ايمونوهيستوشيمى}

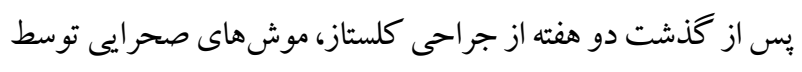

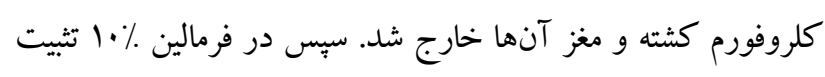

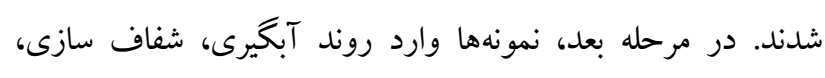
آغشتخى با بارافين و قالب گيرى شدند. بِ إن از تهيه مقاطع سريال 9

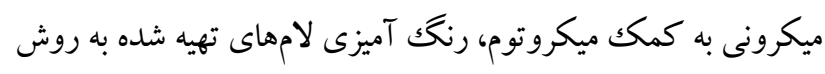

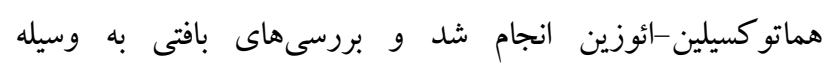

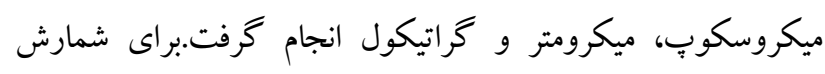

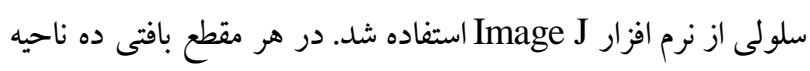
به صورت تصادفى مشخص و شمارش و ميانگين سلولها در هر ميليمتر

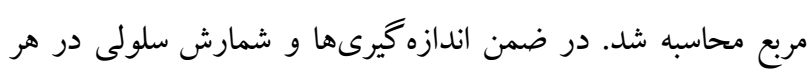

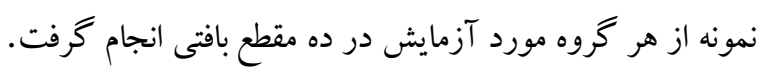

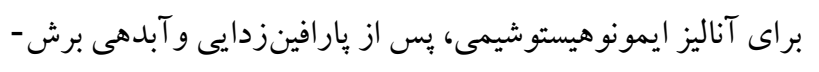

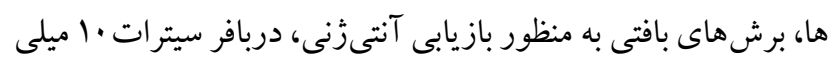

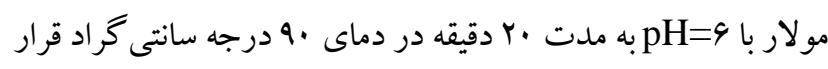

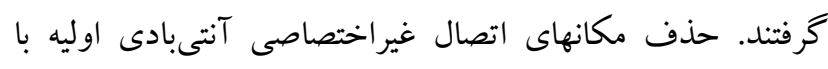

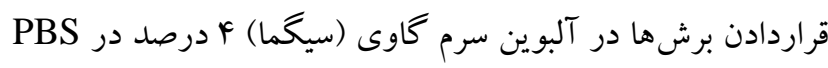

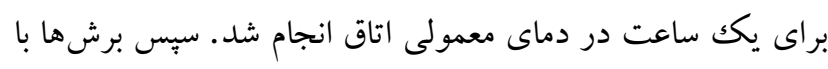

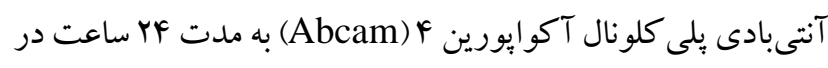



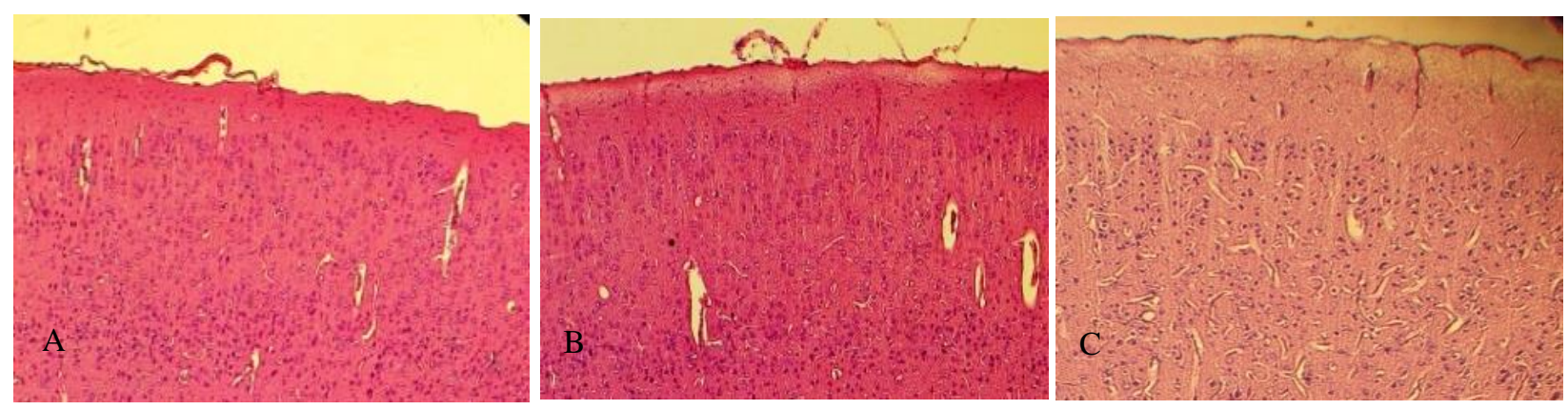

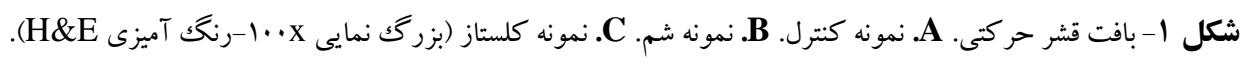

Fig. 1. Motor cortex tissue sections. A. Control sample. B. Sham sample. C. Cholestatic sample. (100X-H\&E).

$$
\text { جدول ا- ضخامت قشر حر كتى و درصد سلولهاى هتروكروماتين در گروههاى شم ، كنترل و كلستاز. }
$$

\begin{tabular}{|c|c|c|}
\hline درصد سلولهاى هتروكروماتين & ضخامت ( & كروه \\
\hline . & $91 / / F \pm 9 / 1$ & كنترل \\
\hline$r / Y q \pm 1 / M A$ & $1 \cdots \pm V / f$ & شم \\
\hline$r \mid / \Delta \pm r / \cdot$ 入羊N & 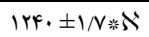 & كلستاز \\
\hline
\end{tabular}

Table 1. Thickness of Motor cortex and Heterochromatin cells percentage in control, sham and cholestasis groups.
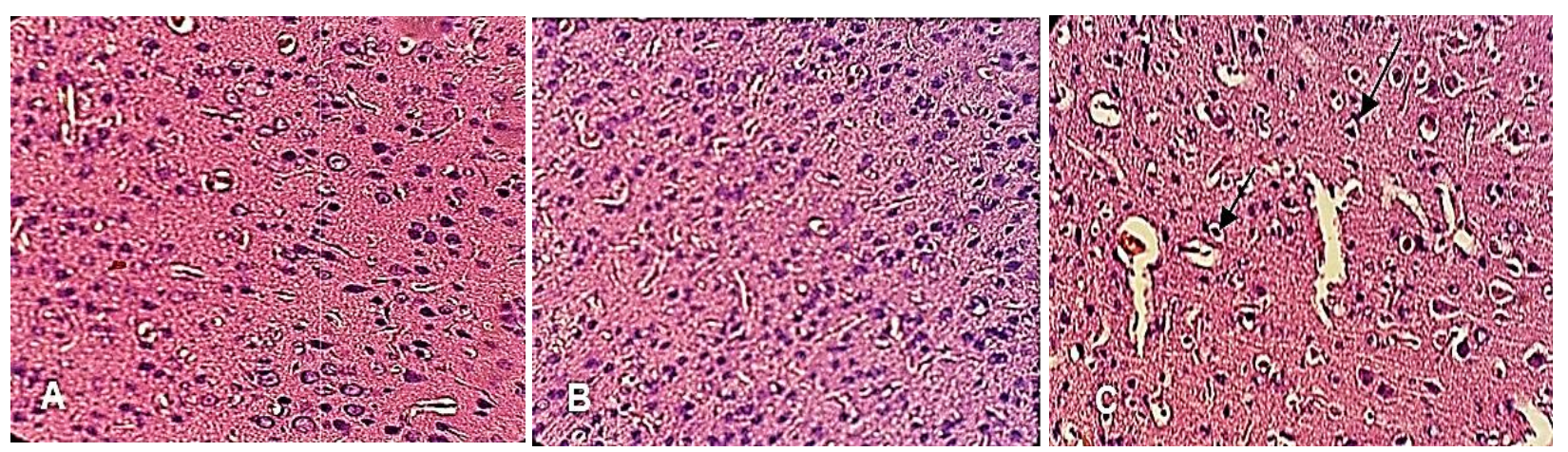

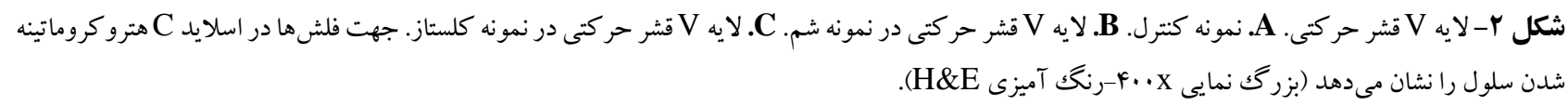

Fig. 2. Motor cortex tissue slides (V layer). A. Control sample. B. Sham sample. C. Cholestatic sample. Heterochromatin cells (black arrows) (400X-H\&E).

مورفولوزى در قشر كه مىتوان به آن اشاره كرد، كاهش تراكم سلولى در نمونههاى كلستاز در مقايسه با نمونهاى شم و كنترل است كه با توجه به عكس هاى مربوطه در سه گروه و درلايه II با بزرگك نمايى يكسان قابل مشاهده است (شكل r و شكل س ب A B C C). نتايج حاصل از تاثير كلستاز بر مقدار AQP در قشر مغز نشان دهنده كاهش ميز ان بروتئين AQP در نمونه هاى كلستاتيك در مقايسه با نمونه هاى كنترل و شم است.
جدول، نشان دهنده معنىدار بودن افزايشهاى هتروكروماتين در نمونه هاى كلستاتيك در مقايسه با نمونههاى شم وكنترل است. همجنين هتروكروماتينه شدن برخى سلولها در قشر حركتى در Vوش هاى صحرايى كلستاتيك مشاهده شد. اين ويثز قشر حركتى به وضوح قابل تشخيص است (شكل C Y). در حاليكه سلولها در نمونههاى شم همانند نمونهاى كنترل بوده و اختلاف معنى دارى در آنها مشاهده نشد (شكل Ar، Br). از ديخر اختلافات 

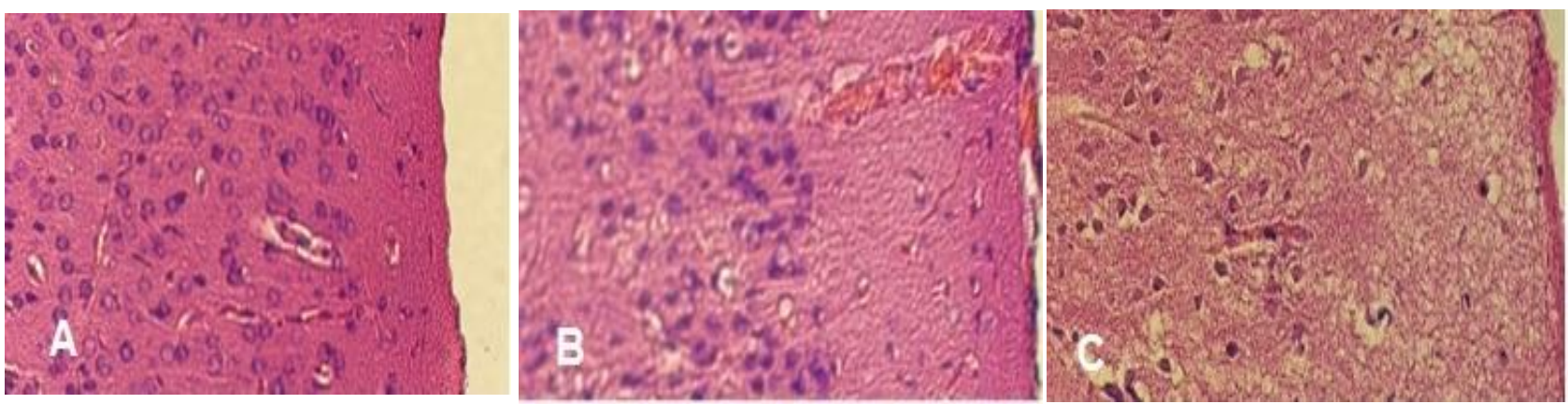

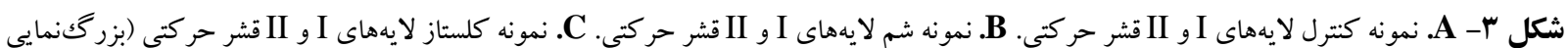

$$
\begin{aligned}
& \text {. H\&E }
\end{aligned}
$$

Fig. 3. Motor cortex tissue slides (I \& II layer). A. Control sample. B. Sham sample. C. Cholestatic sample. (400X-H\&E).
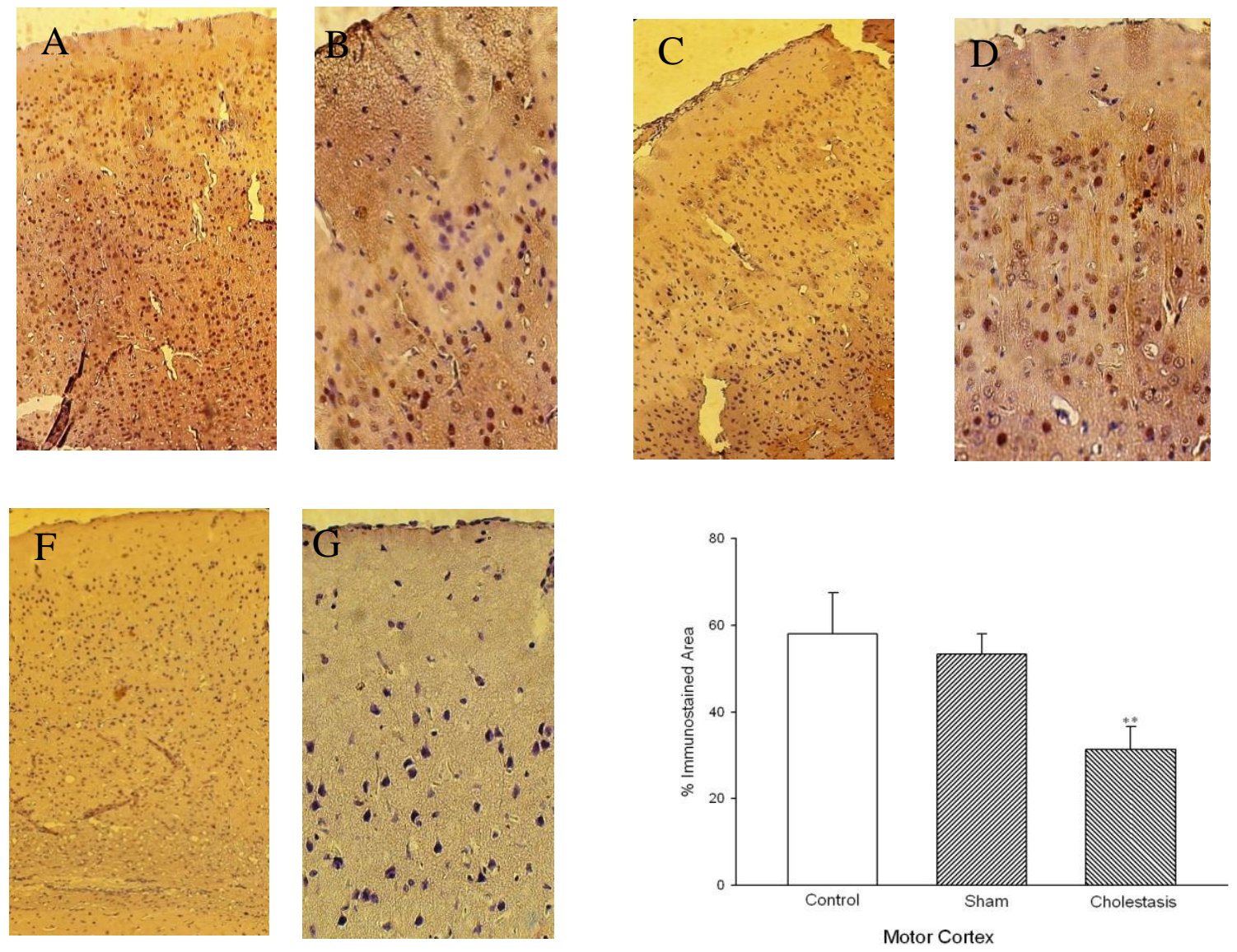

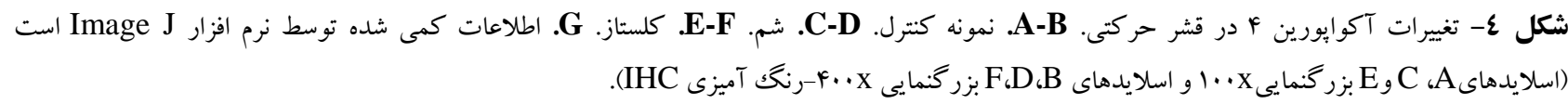

Fig 4. The level of aquaporin 4 in motor cortex. A-B. Control sample. C-D. Sham sample. E-F. Cholestatic sample. G: Image J data. (400X-IHC).

داشته باشد. مشخص شده است كه هياتيك آنسفالوياتى باعث ايجاد تغييراتى در بافت مغز مىشود. در مغز موشهاى كلستاتيكى، نكروز و هترو كروما تينه شدن برخى سلولها مشاهده شده است ( Gharooni

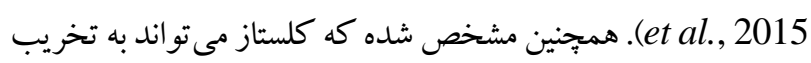

هتروكروماتينه شدن سلولها همراه با كاهش تراكم و كاهش انسجام بافتى، همجنين كاهش مقدار آكوايورين f است. اين انتظار

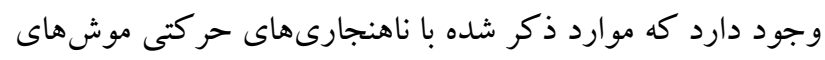

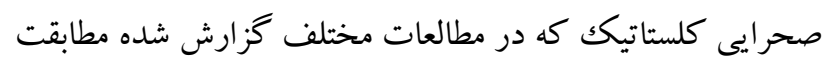


ادم در سندروم كلستاز در ارتباط است (Oryan et al., 2017).

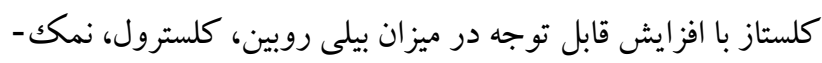

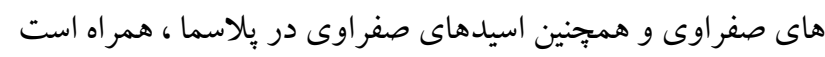
(Kwiatkowski \& Mcgill, 1998; Rodrígu, 2003) مكانيسمهاى مختلفى براى سايتوتو كسيسيتى اسيدهاى صفراوى ييشنهاد شده است كه از آن جمله م توان به تغيير درهومئوستاز

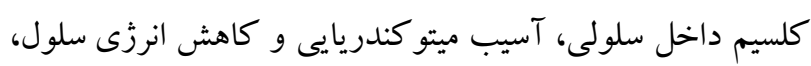

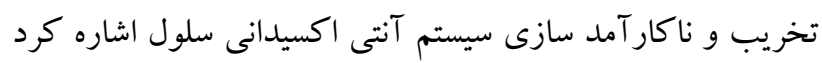

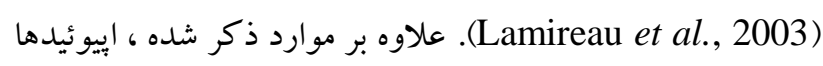
و اندوتو كسينها نيز در خون افزايش مىيابد ( Eslimi et al., 2011). از طرفى ديخر در نقش مهم نوروتو كسين ها به ويزه آمونيا

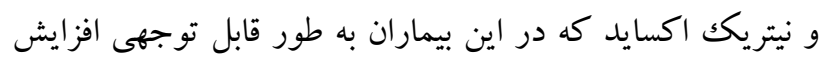

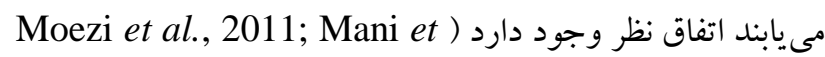
(al., 2001

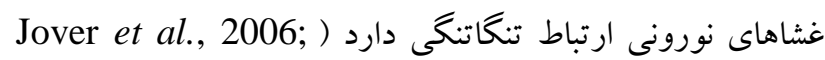
Snyder \& Bredt et al., 1991; Buldanlioglu et al., .(2005; Jayakumar, 2014 بسيارى از بيمارى هاى كبدى با اختلالات مغزى همر اه است كه در

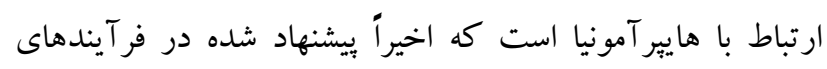

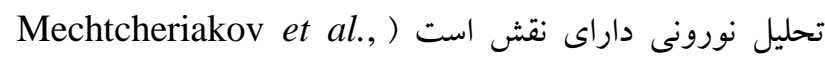

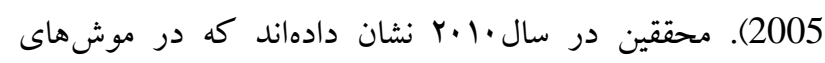

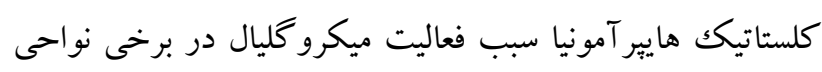

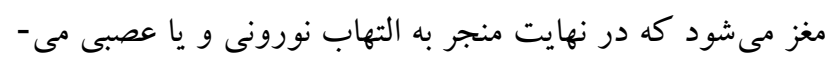
كردد. فاكتور نكروزه كننده تومور م (TNFآسيب ديده بيان مىشود و در آغاز آبشارهاى فرايند آسيبهاى نورونى شركت دارد (Chaparro-Huerta et al., 2002). همجنين طبق مطالعات صورت گرفته در سيروز كبدى بيان

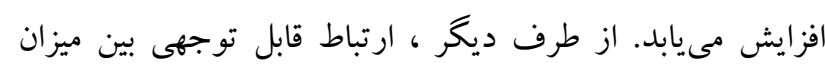
TNF- $\alpha$ به عبارت ديخر هر جه ميزان TNF-

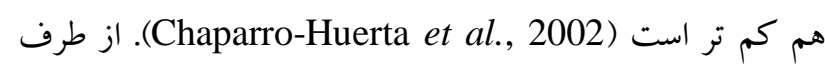

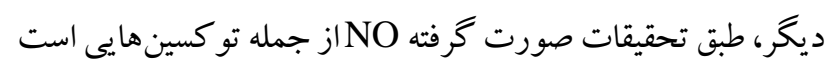
كه در موشهاى كلستاتيك ميزان آن افزايش مى يابد ( Dhanda et

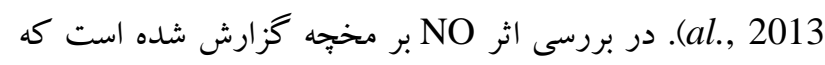

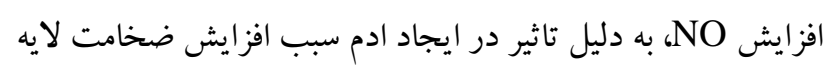

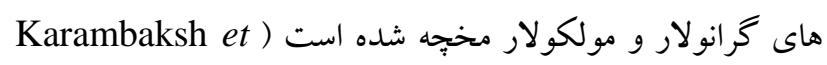

بافت، ايجاد نكروز و هتروكروماتينه شدن هييو كامب منجر شود (Eslimi et al., 2017)

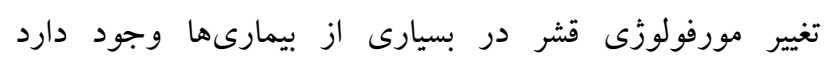

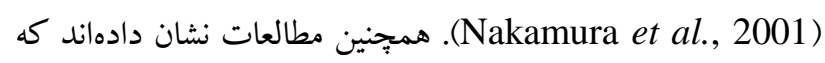
آسيب قشر حركتى مىتواند منجر به قطع هماهنگى ارتباطات

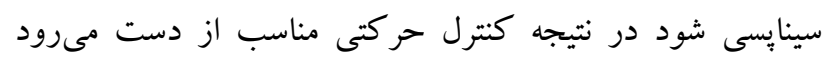

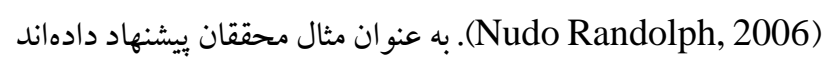

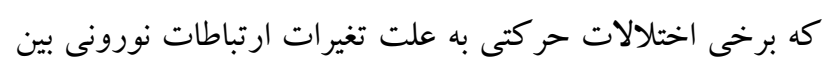
عقدهاى قاعده اى و قشر حركتى است (Leke et al., 2012).

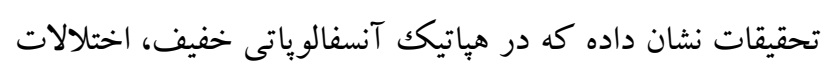

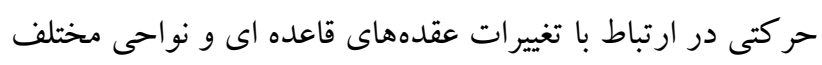

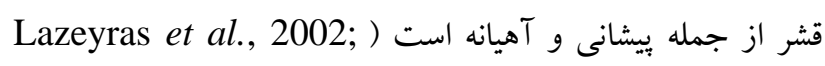
Satanoda et al., 2001

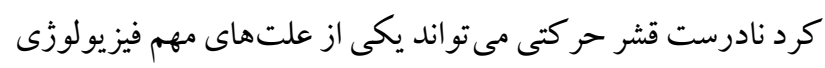
اختلالات حر كتى باشد (Lindenbach \& Bishop, 2013). به فيه

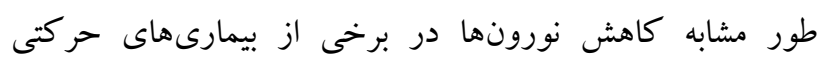

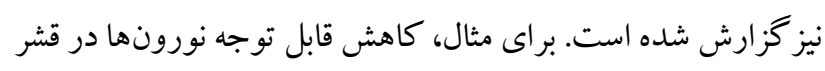

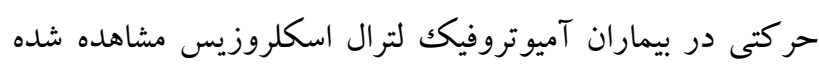
است (Katanoda et al., 2001). همجينين كاهش نورونها در

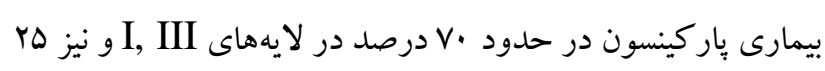

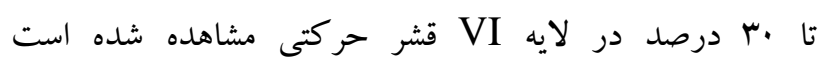
(Lindenbach \& Bishop, 2013) دارد كه كاهش تراكم سلولى ويا هتروكروماتينه بودن برخى از آنها

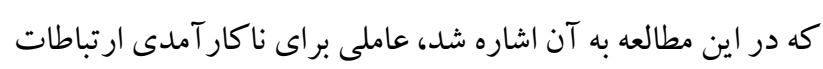

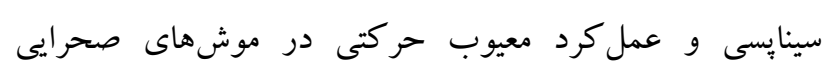

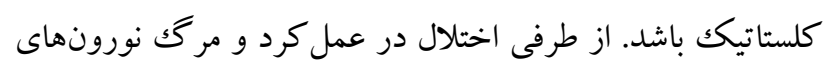

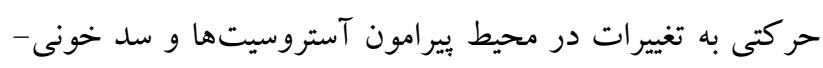

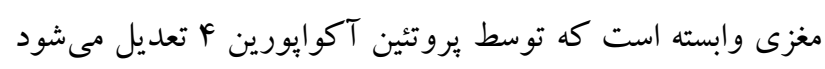
(Bataveljić et al., 2012) (مطالعات نشان مىدهند كه كلستاز

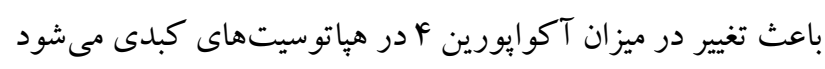
و نفوذ بذيرى به آب كاهش مى يابد (Guillermo et al., 2008).

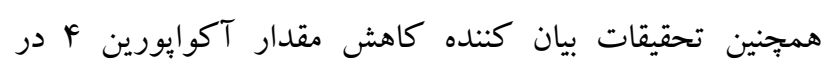
هستهاى فوق بصرى و مجاور بطنى در موشهاى كلستاتيك بود

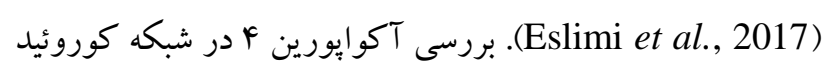
يس از بستن مجراى صفراوى نشان دهنده افزايش آن بود كه با ايجاد 


\section{REFERENCES}

Bataveljić, D., Nikolić, L., Milosević, M., Todorović, N. and Andjus, P.R. 2012. Changes in the astrocytic aquaporin-4 and inwardly rectifying potassium channel expression in the brain of the amyotrophic lateral sclerosis SOD1 (G93A) rat model. - Glia 60: 1991-2003.

Buldanlioglu, S., Turkmen, S., Ayabakan, H.B. and Yenice, N. 2005. Nitric oxide, lipid peroxidation and antioxidantdefence system in patients with active or inactive behcet's disease. - Br. J. Dermatol. 153: 52630.

Butterworth, R.F., Lalonde, R., Power, C., and Baker G.B. 2009. Dehydroepiandrosterone sulphate improves cholestasis-associated fatigue in bile duct ligated rats. - Neurogastroenterol Motil. 21: 1319-1325.

Butz, M., Timmermann, L., Braun, M., Groiss, S.J., Wojtecki, L., Ostrowski, S., Krause, H., Pollok, B., Gross, J., Südmeyer, M., Kircheis, G., Häussinger, D. and Schnitzler, A. 2010. Motor impairment in liver cirrhosis without and with minimal hepatic encephalopathy. - Acta Neurol. Scand. 122: 27-35.

Chaparro-Huerta, V., Rivera-Cervantes, M., TorresMendoza, B. and Beas-Zarate, C. 2002. Neuronal death and tumor necrosis factor-a response to glutamateinduced excitotoxicity in the cerebral cortex of neonatal rats. - Neurosci. Let. 333: 95-98.

Dhanda, S., Kaur, S. and Sandhir, R. 2013. Preventive effect of N-acetyl-L-cysteine on oxidative stress and cognitive impairment in hepatic encephalopathy following bile duct ligation. - Free Radic. Biol. Med. 56: 204-215.

Eslimi Esfahani, D., Oryan, Sh., Nabiuni, M. and Karimian Peiro, M. 2017. The role of cholestasis in brain hippocampus trauma in male Wistar rat. - Nova Biol. Reperta 4: 128-136.

Eslimi Esfahani, D., Oryan, Sh., Nabiuni, M., Karimian Peiro, M. and Gharooni F. 2017. The effect of hepatic impairment on the aquaporin-4 in the paraventricular (PVN) and Supraoptic (SON) nuclei of rat hypothalamus. - Med. Sci. 27: 252-260.

Eslimi, D., Oryan, S., Nasehi, M. and Zarrindast, M.R. 2011. Effects of opioidergic systems upon anxiolyticlike behaviors induced in cholestatic rats. - Pharmacol. 670: 180-185.

Felipo, V. 2013. Hepatic encephalopathy: effects of liver failure on brain function. - Nat. Rev. Neurosci. 14: 851-858.

Gharooni, F., Oryan, Sh., Nabiuni, M., Eslimi Esfahani, D., Hosseinynia, T.S., Karimian Peiro, M. and Parsa, S. 2015. The histopathological effects of cholestasis on hypothalamic paraventricular and supraoptic nucleus on male wistar rats. - Nova Biol. Reperta 1: 77-85.

Gonzalez-Usano, A., Cauli, O., Agusti, A. and Felipo, V. 2014. Pregnenolone sulfate restores the glutamatenitric-oxide-cGMP pathway and extracellular GABA in cerebellum and learning and motor coordination in hyperammonemic rats. - ACS Chem. Neurosci. 19: 100-105.

Guillermo, L., Lehmann Maria, C., Larocca Leandro, R., Soria Raúl, A. and Marinelli. 2008. Aquaporins: Their (al., 2013; Gonzalez-Usano et al., 2014 وجود دارد، يكى از علتهاى ممكن براى افزايش ضخامت قشر حركتى در گروه كلستاتيكك كه در اين مطالعه بررسى شده است افزايش NO باشد. در مجموع اين احتمال وجود دارد كه افزايش اين عوامل باعث ايجاد تغييرات بافتى قشر مغز و به دنبال آن اختلالات حر كتى كردد.

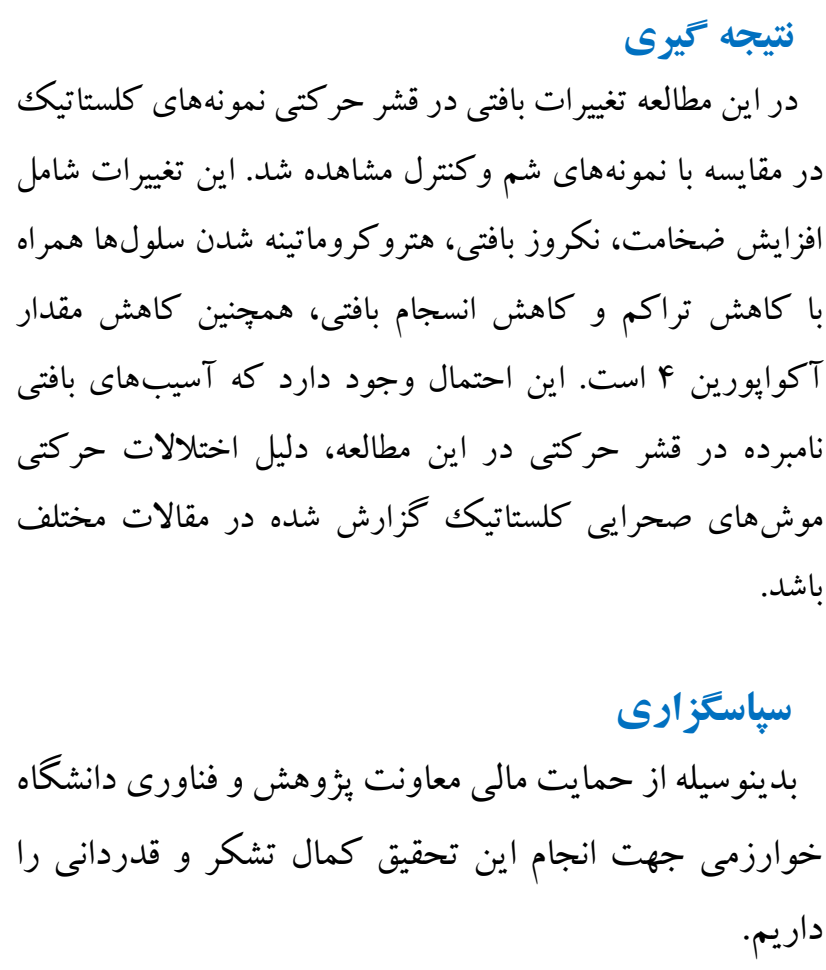


role in cholestatic liver disease. - World $\mathrm{J}$. Gastroenterol. 14: 7059-7067.

Haan, R., Lim, J., van der Burg, S.A., Pieneman, A.W., Nigade, V., Mansvelder, H.D. and de Kock, C.P.J. 2018. Neural representation of motor output, context and behavioral adaptation in rat medial prefrontal cortex during learned behavior. - Front Neural Circuits. 1: 12:75.

Hatsopoulos, G., Harrison, T. and Donoghue, P. 2001. Representations based on neuronal interactions in motor cortex. - Prog. Brain Res.130: 233-44.

Jayakumar, V., Valdes, X.Y., Tong, N., Shamaladevi, W. and Gonzalez, M.D. 2014. Sulfonylurea receptor 1 contributes to the astrocyte swelling and brain edema in acute liver failure. - Norenberg Transl. Stroke Res. 5: 28-37.

Jover, R., Rodrigo, R., Felipo, V. and Insausti, R. 2006. Brain edema and inflammatory activation in bile duct ligated rats with diet-induced hyperammonemia: a model of hepatic encephalopathy in cirrhosis. - Hepatol. 43: 1257 1266.

Karambaksh, A., Noori Mougahi, M., Hassan Zadeh, Gh. and Tak Zaree, N. 2013. Excitatory and inhibitory effects of nitric oxide on weight, size, and histological changes of rat cerebellum. - Tehran Univ. Med. J. 10: 595-600.

Katanoda, K., Yoshikawa, K. and Sugishita, M.A. 2001. Functional MRI study on the neural substrates for writing. Hum. - Brain Mapp. 13: 34-42

Kwiatkowski, A.P. and Mcgill, J.M. 1998. Cholestatic liver diseases in adults. - Gastroenterol. 93: 689-691.

Lamireau, T., Zoltowska, M., Levy, E., Yousef, I., Rosenbaum, J., Tuchweber, B. and Desmoulière A. 2003. Effects of bile acids on biliary epithelial cells: proliferation, cytotoxicity, and cytokine secretion. Life Sci. 72: 1401-1411.

Lazeyras, F., Spahr, L., DuPasquier, R., Delavelle, J., Burkhard, P., Hadengue, A., Hochstrasser, D., Mentha, G., Giostra, E, Terrier, F. and Vingerhoets, F. 2002. Persistence of mild parkinsonism after liver transplantation in patients with preoperative minimal hepatic encephalopathy: a study on neuroradiological and blood manganese changes. Transpl. Int. 15: 188-195.

Leke, R., Oliveira, D.L., Mussulini, B.H.M. and Pereira, M.S. 2012. Impairment of the organization of locomotor and exploratory behaviors in bile ductligated rats. - PLoS One 7: 1-8.

Lindenbach, D. and Bishop, Ch. 2013. Critical involvement of the motor cortex in the pathophysiology and treatment of Parkinson's disease. - Neurosci. Biobehav. Rev. 1838: 1-14.

Magen, I., Avraham, Y., Ackerman, Z. and Vorobiev, L. 2009. Cannabidiol ameliorates cognitive and motor impairments in mice with bile duct ligation. J. Hepatol. 51: 528-534.

Mechtcheriakov, S., Graziadei, I.W., Kugener, A., Schuster, I., Mueller, J., Hinterhuber, H., Vogel, W. and Marksteiner, J. 2006. Motor dysfunction in patients with liver cirrhosis: impairment of handwriting. - J. Neurol. 253: 349-56.

Mechtcheriakov, S., Graziadei, I.W., Rettenbacher, M., Schuster, I., Hinterhuber, H., Vogel, W. and Marksteiner, J. 2005. Diagnostic value of fine motor deficits in patients with low-grade hepatic encephalopathy. - World J. Gastroenterol. 11: 27772780 .

Moayedi, M., Weissman-Fogel, I., Salomons, T. and Crawley, A. 2012. Abnormal gray matter aging in chronic pain patients. - Brain Res. 1456: 82-93.

Mochizuki, Y., Mizutani, T., Shimizu, T. and Kawata, A. 2011. Proportional neuronal loss between the primary motor and sensory cortex in amyotrophic lateral sclerosis. - Neurosci. Lett. 503: 73-75.

Moezi, L., Shafaroodi, H., Sarkar, S. and EmamiRazavi, SH. 2006. Involvement of nitrergic and opioidergic systems in the hypothermia induced by cholestasis in rats. - Pathophysiol. 13: 227-232.

Nakamura, K., Fox, R. and Fisher, E. 2012. CLADA: cortical longitudinal atrophy detection algorithm. NeuroImage 54: 278-289.

Nudo Randolph, J. 2006. Mechanisms for recovery of motor function following cortical damage. Curr. Opin. Neurobiol. 16: 638-644.

Oryan, Sh., Nabiuni, M. and Eslimi Esfahani, D. 2017. Effects of cholestasis on aquaporin 4 choroid plexus of male wistar rat. - Animal Research 11: 134-144.

Rivara, C.B., Sherwood, C.C., Bouras, C. and Hof, P.R. 2003. Stereologic characterizationand spatial distribution patterns of Betz cells in the human primary motor cortex. - Anat. Rec. 270: 137-151.

Rodríguez-Garay, E.A. 2003. Cholestasis: human disease and experimental animal models. - Ann. Hepatol. 2: 150-158.

Ropponen, A., Sund, R., Riikonen, S. and Ylikorkala, O. 2006. Intrahepatic cholestasis of pregnancy as an indicator of liver and biliary diseases: a populationbased study. - Hepatol. 43: 723-728.

Sheen, J.M., Huang, L.T., Hsieh, Ch.S. and Chen, Ch.Ch. 2010. Bile duct ligation in developing rats: temporal progression of liver, kidney, and brain damage. - J. Pedi. Surg. 45: 1650-1658.

Thomson, A.B.R. and Shaffer, E.A. 2008. First principles of gastroenterology, the basis of disease and an approach to management. - Janssen and Ortho. 9: 514-519.

Tripodi, V., Contin, M., Fernández, M.A. and Lemberg, A. 2012. Bile acids content in brain of common duct ligated rats. - Ann. Hepatol. 11: 930-934.

Weiler, N., Wood, L., Yu, J. and Solla, S.A. 2008. Topdown laminar orga-nization of the excitatory network in motor cortex. - Nat. Neurosci. 11: 360-366.

Yasuko, I. and Moon Young, Kim. 2015. Nitric oxide in liver diseases. - Trends Pharmacol. Sci. 36: 524536.

Zhang, Y., Hong, J.Y., Rockwell, C.E., Copple, B.L., Jaeschke, H. and Klaassen, C.D. 2012. Effect of bile duct ligation on bile acid composition in mouse serum and liver. - Liver Int. 32: 58-69. 
How to cite this article:

Eslimi Esfahani, D., Oryan, Sh., Nabiuni., M. and Sadat Hosseinynia, T. 2019. The effects of bile duct ligation on motor cortex region morphology and aquaporin 4 protein concentration in male Wistar rats - Nova Biol. Reperta 6: 1-9.

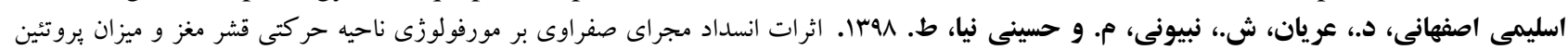

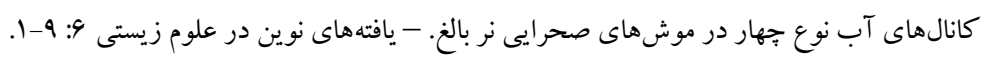

